\title{
Safety of protease inhibitors in HIV-infected pregnant women
}

This article was published in the following Dove Press journal:

HIVIAIDS - Research and Palliative Care

26 September 2013

Number of times this article has been viewed

\author{
Imène Chougrani' \\ Dominique Luton ${ }^{1,2}$ \\ Sophie Matheron ${ }^{3}$ \\ Laurent Mandelbrot ${ }^{2,4}$ \\ Elie Azria ${ }^{1,2}$ \\ 'Department of Obstetrics and \\ Gynecology, Bichat Claude Bernard \\ Hospital, Paris Diderot University, \\ Paris, ${ }^{2}$ Departement Hospitalo- \\ Universitaire "Risk and Pregnancy", \\ Paris, ${ }^{3}$ Department of Infectious and \\ Tropical Diseases, Bichat Claude \\ Bernard Hospital, Paris Diderot \\ University, Paris, ${ }^{4}$ Department of \\ Obstetrics and Gynecology, Louis \\ Mourier Hospital, Paris Diderot \\ University, Colombes, France
}

\begin{abstract}
The dire conditions of the human immunodeficiency virus/acquired immune deficiency syndrome epidemic and the immense benefits of antiretroviral prophylaxis in prevention of mother-to-child transmission far outweigh the potential for adverse effects and undeniably justify the rapid and widespread use of this therapy, despite incomplete safety data. Highly active antiretroviral therapy has now become standard care, and more than half the validated regimens include protease inhibitors. This paper reviews current knowledge of the safety of these drugs during pregnancy, in terms of maternal and fetal outcomes. Transfer of protease inhibitors across the placenta is known to be minimal, and current data about birth defects and fetal malignancies are reassuring. Maternal liver function and glucose metabolism should be monitored in women treated with protease inhibitor-based regimens, but concerns about the development of maternal resistance, should treatment be discontinued, have been shown to be groundless. Neonates should be screened for hematologic abnormalities, although these are rarely severe or permanent and are not usually related to the protease inhibitor component of the antiretroviral combination. Current findings concerning pre-eclampsia and growth restriction are discordant, and further research is needed to address the question of placental vascular complications. The increased risk of preterm birth attributed to protease inhibitors should be interpreted with caution considering the discrepant results and the multitude of confounding factors often overlooked. Although data are thus far reassuring, further research is needed to shed light on unresolved controversies about the safety of protease inhibitors during pregnancy.
\end{abstract}

Keywords: human immunodeficiency virus, pregnancy, protease inhibitors

\section{Introduction}

Protease inhibitors (PIs) are substrate analogs for the human immunodeficiency virus (HIV) aspartyl protease enzyme, which is involved in processing viral proteins by cleaving protein molecules into smaller fragments and thus releasing mature viral particles from infected cells. Once bound to their active site, they block the enzyme from further activity, inhibit the viral maturation process, and block formation of functional virions.

PIs were the second class of antiretroviral drugs developed, and saquinavir (Roche, Basel, Switzerland) was the first PI approved by the US Food and Drug Administration (FDA) in 1995. Since then, PI-based highly active antiretroviral therapy (HAART) regimens have overtaken other HAART combinations, especially in the last decade.

Tremendous progress has been achieved since the ACTG 076 trial $^{1}$ and introduction of antiretroviral therapy to prevent mother-to-child transmission of HIV. The estimated annual number of newborns with HIV worldwide has dropped dramatically,
Correspondence: Elie Azria Service de Gynecologie Obstétrique, Hôpital Bichat Claude Bernard, 46 rue Henri Huchard,

75877 Paris Cedex 18, France

$\mathrm{Tel}+336 \mathrm{I} \mid 525432$

Fax +33 3I 40258819

Email elie.azria@bch.aphp.fr 
falling to 330,000 in $2011,^{2}$ and most of these infections occur in resource-poor countries. In developed countries where the use of HAART became widespread in the late $1990 \mathrm{~s}$, the transmission rate has decreased to around $1 \%$ in recent years. ${ }^{3,4}$

With the availability of antiretroviral drugs increasing globally, the World Health Organization has expanded its recommendations for their use. These new guidelines will drive rapid growth of antiretroviral use in resource-poor countries. Although the immense benefits of antiretroviral prophylaxis in prevention of mother-to-child transmission and the dire conditions of the HIV/acquired immune deficiency syndrome (AIDS) epidemic far outweigh the potential for adverse effects, there is now an urgent need to document better the safety of antiretroviral therapy.

This is certainly a difficult task, especially given that the available literature on potentially rare side effects relies mainly on retrospective and cohort studies. Moreover, the great heterogeneity in populations creates major difficulties in distinguishing the side effects of different classes of antiretroviral drugs from one another and from disease complications. Discriminating class-specific effects is indeed a problem, because current HAART regimens (and thus most of the available literature) are based on combination therapies, including reverse transcriptase inhibitors (RTIs). Ongoing studies comparing different single-class regimens might overcome this difficulty. In the meantime, class-specific adverse effects can reasonably be deduced from data from nonpregnant populations and the well documented effects of RTIs. ${ }^{5}$ Figure 1 summarizes the safety concerns associated with in utero PI exposure.

\section{Protease inhibitor regimens}

Based on available data suggesting that transmission rates are similar in women with higher CD4+T cell counts regardless of whether they receive monotherapy or HAART, ${ }^{6}$ the World Health Organization ${ }^{7}$ recommends both options, without stating any preference for one over the other. However,
HAART has been the standard care in high-resource countries and its use for all women is programmatically appealing. The prolonged half-life of non-nucleoside RTIs makes them less suitable as part of a short course of treatment for prevention of mother-to-child transmission only. ${ }^{8}$ Triple nucleoside RTI regimens have showed similar transmission rates and better viral load suppression than PI-based HAART, ${ }^{9}$ but higher rates of treatment failure in nonpregnant women have been reported when the baseline viral load is $>100,000$ HIV RNA copies/mL plasma. ${ }^{10}$ Based on these data, the British HIV Association recommends that HAART, when indicated to prevent mother-to-child transmission, should be based on boosted PI, in the absence of specific contraindications. ${ }^{8}$

In the US, in utero exposure to PIs rose from 15\% in 1997 to $86 \%$ in $2009 .{ }^{11}$ It was estimated that in 2009 , in northern countries, $57.6 \%$ of regimens during pregnancy were based on ritonavir-boosted PIs (Abbott, North Chicago, IL, USA), ${ }^{12}$ and $79 \%$ of the children were exposed to a ritonavir-boosted PI regimen. ${ }^{11}$

In 2011, Griner et $\mathrm{al}^{11}$ used data from the Pediatric HIV/AIDS Cohort Study Surveillance Monitoring for ART Toxicities study, a US-based prospective cohort study of HIV-exposed but uninfected children, to assess temporal trends in the use of antiretroviral therapy during pregnancy. PIs were the most common class of drugs observed after triple nucleoside RTIs. The most common PI since 2007 has been lopinavir coformulated with ritonavir (Abbott). In 2009, lopinavir/ritonavir exposure was more than double that of the next most common PI, atazanavir (Bristol-Myers Squibb, New York City, NY, USA) at 55\% versus 20\%, respectively. Other PIs used included nelfinavir (Roche), the most common PI from 1998 to 2006, and indinavir (Merck, Whitehouse Station, NJ, USA), the second most common PI from 1998 to 2000. Use of amprenavir (GlaxoSmithKline, London, UK), fosamprenavir (GlaxoSmithKline), saquinavir (Roche), tipranavir (Boehringer Ingelheim, Ingelheim, Germany), and therapeutic doses of ritonavir were also reported. Ritonavir boosting was generally common in
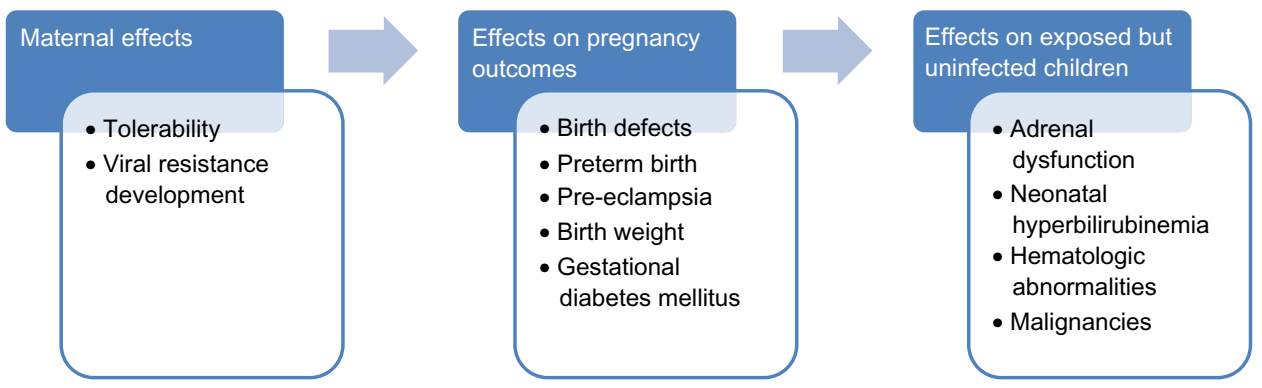

Figure I Concerns raised by the use of protease inhibitors during pregnancy. 
later years (Figure 2), although it varied according to the other drug. ${ }^{11}$

\section{Maternal adverse effects Development of viral resistance}

Current guidelines suggest that antiretroviral therapy should be discontinued after delivery if indicated solely for the prevention of mother-to-child transmission. ${ }^{8}$ However, significant concerns remain about the possible emergence of resistance and the limitation of future therapeutic options for women receiving short-term antiretroviral therapy. A recent study addressing this question reported no clinically significant resistance 4-8 weeks post partum in 40 women receiving PI-based HAART to prevent mother-to-child transmission. ${ }^{13}$ Similarly, no clinically significant drug resistance mutations were found a month after discontinuation of therapy in a subpopulation of the Mma Bana cohort. ${ }^{14}$

The analysis by Briand et al of 1,116 women enrolled in the French National Agency for Research (ANRS) French Perinatal Cohort between 2005 and 2009 showed that PI-based combinations during pregnancy were not any less effective in women previously exposed to various regimens of antiretroviral prevention of mother-to-child transmission, compared with those receiving them for the first time. ${ }^{15}$ On the other hand, Ellis et al observed high resistance rates among women who stopped suppressive nelfinavir-based antiretroviral therapy after pregnancy. ${ }^{16}$ These results are limited by the size of the studies and the absence of data about either treatment adherence throughout pregnancy or the clinical significance of the resistance.
Considering their established immunovirologic efficacy, PI-based regimens are likely to prevent the emergence of resistance mutations. Although suboptimal therapy compliance may be partly responsible for resistance development, further studies are needed to investigate whether certain antiretroviral classes and regimens are superior to others in terms of risk of viral resistance.

\section{Maternal tolerability}

Although rarely severe, maternal adverse effects of antiretroviral therapy, mainly hepatic and hematologic, are not infrequent. Regardless of severity, better tolerability of antiretroviral regimens is crucial for improving adherence and immunovirologic efficacy. A recent study showed that the tolerability of antiretroviral regimens in pregnancy did not differ by class, but found differences between individual drugs. The PI that women found the least tolerable were nelfinavir. ${ }^{17}$

Findings concerning hepatotoxicity in HIV-infected pregnant women are discordant and focus mainly on the severe side effects of nevirapine (Boehringer Ingelheim). ${ }^{18-20}$ High-dose ritonavir (1,200 mg/day) has been associated with an increased risk of hepatotoxicity compared with other antiretroviral regimens. ${ }^{21}$ However, high-dose ritonavir is no longer used as first-line treatment. Instead, because it is a potent inhibitor of cytochrome P450 3A4 metabolism, it is increasingly coadministered with other PIs, such as lopinavir, saquinavir, and indinavir, at a very low dose to improve bioavailability and prolong the elimination half-life of these drugs. This strategy makes dosing schedules easier to comply with and enhances efficacy.

In a cohort of nompregnant patients reported by Sulkowski et al, grade 3 or 4 liver enzyme elevations were

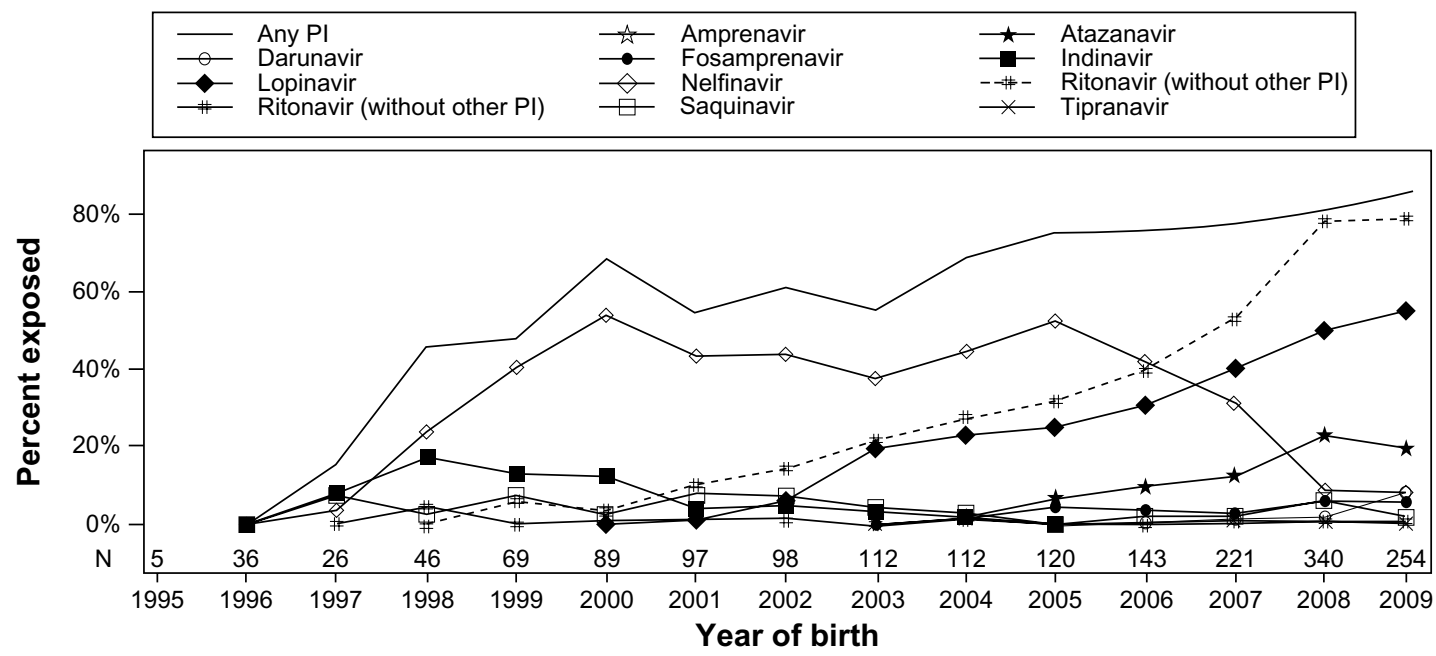

Figure 2 Trends for in utero exposure to PI.

Note: Copyright (C) 20II, Mary Ann Liebert, Inc. publishers. Reproduced with permission from Griner R, Williams PL, Read JS, et al. In utero and postnatal exposure to antiretrovirals among HIV-exposed but uninfected children in the United States. AIDS Patient Care STDS. 20I I;25(7):385-394."

Abbreviation: Pl, protease inhibitor. 
observed in $12 \%$ of patients starting their first PI-based antiretroviral therapy. Lopinavir/ritonavir was not associated with a significantly higher risk of hepatotoxicity compared with a nelfinavir-based regimen. ${ }^{22}$ Given our insufficient knowledge of the mechanisms of hepatotoxicity and in the absence of reassuring data, the role of PIs in this finding cannot be ruled out, and liver function should be monitored. Furthermore, it is often difficult to distinguish antiretroviral liver toxicity from pregnancy-related liver disorders.

Atazanavir use is also associated with an increased risk of elevated serum bilirubin as a result of uridine diphosphate glucuronosyl transferase $1 \mathrm{~A} 1$ inhibition, ${ }^{23,24}$ which has also been reported, albeit to a lesser extent, with indinavir. ${ }^{25}$ Concerns have also been raised about an increased risk of kidney stones in patients receiving atazanavir, especially if associated with tenofovir. ${ }^{26}$

\section{Pregnancy outcomes Birth defects}

Due to their high degree of plasma protein binding and their backward transport through P-glycoprotein, placental transfer of PIs is minimal or absent, although the level may differ according to the specific substance (Table 1). These findings have been confirmed by studies using an ex vivo placental perfusion model for lopinavir. ${ }^{27,28}$ Other ex vivo studies have showed that the clearance index is lowest for saquinavir, ${ }^{29}$ low for ritonavir, ${ }^{30}$ and higher for amprenavir. ${ }^{31}$ Likewise, in vivo studies have confirmed the minimal placental transfer of PIs, ${ }^{32-34}$ except for atazanavir, which has been shown to cross the placenta. ${ }^{35}$

Available data on teratogenicity has been gathered from various sources, including animal studies, therapeutic trials, cohort and surveillance studies, and the US Antiretroviral Pregnancy Registry. This registry was established in 1989 to collect data on birth defects after pregnancy exposures to antiretroviral therapy and conforms to FDA guidelines for pregnancy exposure registries. Its data can be considered robust and reliable.

Registry data indicate that the prevalence of birth defects for first trimester and overall prenatal exposure to lopinavir/ ritonavir is similar to the population-based comparator rate of $2.67 \% .{ }^{36}$ No pattern of birth defects suggestive of a common etiology has been seen. ${ }^{36}$ Similarly, according to a study funded by Bristol-Myers Squibb, the prevalence of birth defects for exposure to atazanavir during the first and the second/third trimester, as well as overall exposure, does not differ from the general population rate for birth defects. $^{37}$

However, the current absence of a statistically significant association between PI exposure and a higher birth defect

Table I Safety classification and placental transfer of Pls for use in pregnancy

\begin{tabular}{|c|c|c|c|}
\hline $\begin{array}{l}\text { FDA pregnancy } \\
\text { category }\end{array}$ & Interpretation & $\mathbf{P I}$ & $\begin{array}{l}\text { Placental } \\
\text { transfer }\end{array}$ \\
\hline A & $\begin{array}{l}\text { Adequate, well controlled studies in pregnant women have not } \\
\text { shown an increased risk of fetal abnormalities in the fetus in any } \\
\text { trimester of pregnancy. }\end{array}$ & & \\
\hline B & $\begin{array}{l}\text { Animal studies have revealed no evidence of harm to the fetus; } \\
\text { however, there are no adequate and well controlled studies in } \\
\text { pregnant women. } \\
\text { Or } \\
\text { Animal studies have shown an adverse effect, but adequate } \\
\text { and well-controlled studies in pregnant women have failed to } \\
\text { demonstrate a risk to the fetus in any trimester. }\end{array}$ & $\begin{array}{l}\text { Ritonavir } \\
\text { Saquinavir } \\
\text { Atazanavir } \\
\text { Nelfinavir } \\
\text { Darunavir }\end{array}$ & $\begin{array}{l}\text { Low } \\
\text { Low } \\
\text { Yes } \\
\text { Low } \\
\text { ND }\end{array}$ \\
\hline C & $\begin{array}{l}\text { Animal studies have shown an adverse effect and there are no } \\
\text { adequate and well controlled studies in pregnant women. } \\
\text { Or } \\
\text { No animal studies have been conducted and there are no } \\
\text { adequate and well conducted studies in pregnant women. }\end{array}$ & $\begin{array}{l}\text { Indinavir } \\
\text { Lopinavir } \\
\text { Fosamprenavir } \\
\text { Amprenavir } \\
\text { Tipranavir }\end{array}$ & $\begin{array}{l}\text { Low } \\
\text { Low } \\
\text { ND } \\
\text { ND } \\
\text { ND }\end{array}$ \\
\hline $\mathrm{D}$ & $\begin{array}{l}\text { Adequate well controlled or observational studies in pregnant } \\
\text { women have demonstrated a risk to the fetus. } \\
\text { However, the benefits of therapy may outweigh the potential risk. }\end{array}$ & & \\
\hline$X$ & $\begin{array}{l}\text { Adequate well controlled or observational studies in animals or } \\
\text { pregnant women have demonstrated positive evidence of fetal } \\
\text { abnormalities or risks. Use of the product is contraindicated in } \\
\text { women who are or may become pregnant. }\end{array}$ & & \\
\hline
\end{tabular}

Abbreviations: ND, no data available; FDA, Food and Drug Administration; PI, protease inhibitor. 
prevalence should be interpreted cautiously. Because these outcomes are rare, the reassuring data might result simply from the limited sample size. Given that the currently used PIs are in either FDA pregnancy category B or C (Table 1), monitoring the potential teratogenic effects of these drugs remains necessary.

\section{Preterm birth}

Although numerous studies have addressed the question of a potential association between PI-based HAART and preterm birth, it remains controversial. Since the first European study brought this issue to light in 2000, several others, emphasizing the role of PIs and early onset of therapy, have confirmed the risk. ${ }^{38-40}$ It has been hypothesized that the physiopathology of preterm birth in the context of PI-based HAART involves immune reconstitution with cytokine shifts that induce the premature onset of labor, rather than any fetal or uteroplacental cause. ${ }^{41,42}$ This mechanism might explain why the risk of preterm birth is highest when therapy onset is earliest. Another potential pathway is the impact on the maternal and fetal adrenal axes involved in spontaneous preterm delivery through disruption of the glucocorticoid metabolism induced by ritonavir-associated inhibition of cytochrome P450 2A4. ${ }^{43}$

Another particularity of HAART regimens including PIs is that they were initially a preferential treatment for women with more advanced HIV disease, which in itself is a risk factor for preterm birth. This confounding element might thus account for (some of) the increased risk of prematurity observed in this group.

Studies addressing this problem of confounding by indication have reported no association between preterm birth and PI regimens, ${ }^{44}$ not even with early exposure to therapy. ${ }^{45,46}$ More recently a study based on the ANRS French Perinatal Cohort implicated ritonavir boosting. After adjusting for immunovirologic status and known risk factors, Sibiude et al showed that ritonavir-boosted PIs are associated with a higher risk of induced preterm birth and of maternal metabolic and vascular complications, compared with non-boosted PIs. No causal relation was established, but immune restoration cannot entirely explain this effect on induced preterm birth. ${ }^{47}$

Evidently an answer to this question requires more data. Two randomized trials in limited-resource countries have taken important steps in this direction. The Kesho Bora study $^{6}$ randomized 882 HIV-infected women with CD4+ $\mathrm{T}$ cell counts of $200-500$ cells $/ \mathrm{mm}^{3}$ to a PI-based regimen versus zidovudine with a single dose nevirapine at the onset of labor. Antiretroviral therapies (except for a single dose of nevirapine) began between 28 and 36 weeks of gestation. Preterm birth rates did not differ between the two groups. These results, however, were contradicted by those of the Mma Bana trial, which randomized 560 women with CD4+ T cell counts $\geq 200$ cells $/ \mathrm{mm}^{3}$ to a PI-based regimen versus a triple nucleoside RTI regimen, both started during the third trimester of gestation. This study reported a higher risk of preterm birth in the PI group, but no increase in rates of infant hospitalization or mortality. ${ }^{48}$ The later start of HAART in the Kesho Bora study might explain this discrepancy.

Given the conflicting findings of the current studies, it is too early to rush into recommendations without validation from further research. It is currently estimated that for every $100 \mathrm{HIV}$ transmissions prevented with HAART, rather than monotherapy, 63 additional preterm births occur, including 23 before 32 weeks of gestation. ${ }^{49}$ Interpretation of these findings requires additional information about the morbidity, mortality, and costs associated with these outcomes. Larger multisite international studies could shed further light on this important question.

\section{Birth weight}

Observational studies of varying levels of evidence report discordant data about the potential effect of PI-based regimens on birth weight. These discrepancies might be partly explained by the failure to discriminate between infants who are small-for-gestational age (SGA) and those with a low birth weight attributable to preterm birth.

Some authors report statistically significant SGA associated with HAART use (with or without PIs).$^{50-52}$ Furthermore, in 2011, Parekh et al described an association between prepregnancy HAART continued throughout pregnancy (without specifying PI use) and very SGA neonates (less than the third percentile). ${ }^{53}$

None of these studies implicated PIs directly, and more specific studies have reported no association between PIbased regimens and SGA. ${ }^{40,54,55}$ Likewise, the randomized Kesho Bora trial showed no significant increase in low $(<2,500 \mathrm{~g})$ or very low $(<1,500 \mathrm{~g})$ birth weights in the PI-based HAART arm. ${ }^{6}$ The results from the ANRS French Perinatal cohort also suggest that HAART during pregnancy does not increase the incidence of SGA infants. ${ }^{56}$

In 2009, Ivanovic et al reported that birth weight $<2,500 \mathrm{~g}$ is associated with the ratio of antiretroviral drug concentrations in maternal and cord plasma. ${ }^{57}$ In view of both this pharmacologic rationale and the low transplacental transfer of PIs (which implies low cord-to-maternal plasma ratios), an association between low birth weight and PI-based 
regimens seems unlikely. These results suggest that PIs are not specifically associated with increased SGA, but this needs to be confirmed by further research.

\section{Pre-eclampsia}

The etiology of pre-eclampsia is multifactorial but the role of the immune system as a causal factor is now well established. Immune modifications induced by HIV might thus intervene in the development of pre-eclampsia. The significantly lower incidence of pre-eclampsia reported in untreated HIV-infected patients than in women treated with HAART led to the suggestion that the immune deficiency induced by HIV infection could prevent the development of pre-eclampsia, but that this "benefit" is lost with treatment. ${ }^{58}$ Other authors have proposed that HAART causes pre-eclampsia by a direct toxic effect on the liver that impairs the synthesis and secretion of retinolbinding proteins and leads to the reduced serum retinol concentrations that have been associated with pre-eclampsia. ${ }^{59}$

Since then, contradictory data about this association have been reported. An adequately powered South African study showed no reduction in the risk of pre-eclampsia in untreated HIV patients, ${ }^{60}$ and a prospective Brazilian study reported a significantly lower rate of pre-eclampsia among treated (HAART or monotherapy) HIV-infected women compared with uninfected controls. ${ }^{61}$

In contrast, Suy et al reported in 2006 that HIV infection treated with HAART before pregnancy was associated with a significantly higher risk of pre-eclampsia and fetal death and that this risk did not return to baseline with therapy, but actually increased. The relevance of these results is limited by the fact that odd ratios were not adjusted for baseline risk factors such as chronic hypertension or diabetes mellitus. ${ }^{62}$ More recently, two North American studies found no increase in the pre-eclampsia rates among treated HIV-infected women, regardless of the type of therapy. ${ }^{54,63}$

These discrepancies may be related to differences in the study populations and their underlying medical morbidities. Nonetheless, the inconsistency of the available results leaves immense uncertainty as to whether HIV lowers or increases the rate of pre-eclampsia and how antiretroviral therapy affects this rate. Further research is needed to answer this question, which might be addressed as a physiopathologic entity conjointly with other placental vascular complications, such as growth restriction.

\section{Gestational diabetes mellitus}

PIs have been associated with glucose and lipid metabolism abnormalities in nonpregnant populations, even in the absence of HIV infection. Several studies have demonstrated intraclass differences in the effect of PIs on glucose metabolism. ${ }^{64-66}$ Analysis of the PACTG 316 study revealed an increased risk of gestational diabetes mellitus in women receiving PI-based HAART before or early in pregnancy. ${ }^{67}$ Prospective studies have reported similar results. ${ }^{68,69}$ However, other authors have found no association between PI use and glucose intolerance in either retrospective studies ${ }^{45,70}$ or larger prospective trials. $^{71}$

It is thus too early to reach conclusions, and further investigations are needed to assess the association between PIs and gestational diabetes mellitus. In the meantime, pregnant women receiving PI regimens should be screened for gestational diabetes mellitus and monitored closely during pregnancy. On the other hand, in animal models, fetal and maternal exposure to lopinavir is reduced in subjects with gestational diabetes mellitus. If confirmed in humans, this drug-disease interaction reducing the bioavailability of lopinavir would have to be taken into account and exposure targets monitored carefully in women with gestational diabetes mellitus. $^{72}$

\section{Uninfected children Malignancies}

Animal studies have found some antiretroviral drugs to be genotoxic, ${ }^{73,74}$ thus raising concerns about the carcinogenic potential of perinatal exposure to such therapy. Initial results from cohorts of antiretroviral-exposed children report a reassuring lack of malignancies. ${ }^{75}$ Although no current evidence suggests an increased risk of childhood malignancies, this risk cannot be ruled out, especially given that most of the published studies have investigated the relatively short-term effects of zidovudine. Longer follow-up of exposed and uninfected children until adulthood is needed, but might be very challenging. Collecting information by cross-checking databases is feasible and would be most valuable. Although adequate data discriminating between drug classes are unavailable, PIs appear unlikely to be carcinogenic; indeed, animal studies report nelfinavir, among other PIs, to have anticarcinogenic properties. ${ }^{57,76,77}$

\section{Neonatal hyperbilirubinemia}

Atazanavir is the second most commonly used PI during pregnancy. ${ }^{11}$ It is known to cause serum bilirubin to rise by inhibiting uridine diphosphate glucuronosyltransferase 1A1, ${ }^{23,24}$ which indinavir also does, albeit to a lesser extent. ${ }^{25}$ Atazanavir use during pregnancy might therefore exacerbate physiologic hyperbilirubinemia in neonates and thus create the risk of 
severe neurologic impairment. Recent studies report elevated serum bilirubin in neonates born to mothers treated with atazanavir. ${ }^{78,79}$ Whether this neonatal hyperbilirubinemia is due to placental transfer of unconjugated bilirubin from the mother or to the direct effect of transplacental atazanavir on fetal bilirubin metabolism is uncertain, but the cases reported were rarely clinically significant and never severe. These results are consistent with current guidelines, ie, atazanavir is now a preferred PI, which can be continued or initiated during pregnancy, but its use mandates close monitoring of bilirubin levels in mothers and their babies. ${ }^{9}$

\section{Hematologic abnormalities}

A number of studies have reported subclinical hematologic abnormalities in uninfected infants exposed to both HIV and antiretroviral drugs. ${ }^{80-82}$ The duration of follow-up in these studies has varied, but generally anemia has seemed to be transient, whereas neutropenia and lymphopenia have been more prolonged. ${ }^{83}$ These abnormalities appear to be negatively related to the duration of exposure, and in utero exposure to combination treatment, compared with monotherapy, was associated with greater depletion than monotherapy. ${ }^{52,54}$ Combination antiretroviral therapy contained a PI in 19\% of cases ${ }^{52}$ although the analysis did not consider the composition of the combination.

The clinical significance of these findings is unclear, but further monitoring of antiretroviral therapy-related hematopoietic effects is needed. Complementary research is needed to determine the mechanisms of these effects and whether they are class-dependent.

\section{Adrenal dysfunction}

A recent retrospective cross-sectional analysis of the database from the French national screening for congenital adrenal hyperplasia and the ANRS French Perinatal Cohort shows that newborns exposed in utero to lopinavir/ritonavir and receiving it as a postnatal treatment were more likely than those receiving zidovudine to have transient adrenal dysfunction with increased 17-OH progesterone levels. ${ }^{84}$ Further studies are needed to test the hypothesis of whether lopinavir/ ritonavir acts as an inhibitor of adrenal steroid synthesis in fetuses and newborns.

\section{Conclusion}

This review regarding the adverse effects of PIs during pregnancy highlights the many areas in which discrepancies exist or data are lacking. We must acknowledge that this is a synthetic and not systematic review, and does not apply the specific methodology for systematic reviews or meta-analyses. The increasing exposure to antiretroviral therapy, including HAART, in resource-poor countries, calls for a thorough assessment. In these settings, large randomized prospective trials have shed light upon such disputed questions as growth restriction and preterm birth. ${ }^{20,21}$ Such trials might be the key to improving our knowledge of the safety of antiretroviral drugs, as their power and design might make it possible to discriminate class-related adverse effects, which are a major concern. This issue was appropriately addressed in the French ANRS 135 PRIMEVA trial, the preliminary results of which were presented at the 2011 Conference on Retroviruses and Opportunistic Infections. ${ }^{85}$ In this Phase II/III multicenter trial performed in France, untreated pregnant women with a baseline viral load $<30,000$ copies/mL and CD4+ T $\geq 350$ cells/ $\mu \mathrm{L}$ were randomized to receive one of two possible treatments from 26 weeks of gestation to delivery: open-label lopinavir/ ritonavir 400/100 mg twice daily alone (monotherapy group, $\mathrm{n}=69$ ) or combined with zidovudine/lamivudine $300 / 150 \mathrm{mg}$ twice daily (triple therapy group, $\mathrm{n}=36$ ). The ongoing analyses within this trial to evaluate the potential benefits of nucleoside-sparing in terms of toxicity could help to isolate the specific effects of PIs.

Assessing the safety of PIs and antiretroviral drugs in general needs further and longer-term monitoring. Because such adverse effects are likely to be rare and might occur later in childhood, establishing registries in resource-poor countries and maintaining participation in existing ones is crucial. At this time, based on what we now know, the benefits of PI-based HAART regimens far outweigh the potential side effects. Most PIs can be considered safe for use during pregnancy, although precautions need to be taken with certain patients and newer substances.

\section{Disclosure}

The authors report no conflicts of interest in this work.

\section{References}

1. Connor EM, Sperling RS, Gelber R, et al. Reduction of maternal-infant transmission of human immunodeficiency virus type 1 with zidovudine treatment. Pediatric AIDS Clinical Trials Group Protocol 076 Study Group. N Engl J Med. 1994;331(18):1173-1180.

2. Ghanotakis E, Miller L, Spensley A. Country adaptation of the 2010 World Health Organization recommendations for the prevention of mother-to-child transmission of HIV. Bull World Health Organ. 2012;90(12):921-931.

3. Mandelbrot L, Landreau-Mascaro A, Rekacewicz C, et al. Lamivudinezidovudine combination for prevention of maternal-infant transmission of HIV-1. JAMA. 2001;285(16):2083-2093.

4. Townsend CL, Cortina-Borja M, Peckham CS, Tookey PA. Trends in management and outcome of pregnancies in HIV-infected women in the UK and Ireland, 1990-2006. BJOG. 2008;115(9):1078-1086. 
5. Thorne C, Newell ML. Safety of agents used to prevent mother-tochild transmission of HIV: is there any cause for concern? Drug Saf. 2007;30(3):203-213.

6. Kesho Bora Study G, de Vincenzi I. Triple antiretroviral compared with zidovudine and single-dose nevirapine prophylaxis during pregnancy and breastfeeding for prevention of mother-to-child transmission of HIV-1 (Kesho Bora study): a randomised controlled trial. Lancet Infect Dis. 2011;11(3):171-180.

7. World Health Organization. Global Monitoring Framework and Strategy for the Global Plan Towards the Elimination of new HIV infections Among Children by 2015 and Keeping Their Mothers Alive (EMTCT). Geneva, Switzerland: World Health Organization; 2012.

8. Taylor GP, Clayden P, Dhar J, et al. British HIV Association guidelines for the management of HIV infection in pregnant women 2012. HIV Med. 2012;13 Supp1 2:87-157.

9. Shapiro RL, Hughes MD, Ogwu A, et al. Antiretroviral regimens in pregnancy and breast-feeding in Botswana. N Engl J Med. 2010; 362(24):2282-2294.

10. Williams I, Churchill D, Anderson J, et al. British HIV Association guidelines for the treatment of HIV-1-positive adults with antiretroviral therapy 2012. HIV Med. 2012;13 Suppl 2:1-85.

11. Griner R, Williams PL, Read JS, et al. In utero and postnatal exposure to antiretrovirals among HIV-exposed but uninfected children in the United States. AIDS Patient Care STDS. 2011;25(7):385-394.

12. Baroncelli S, Tamburrini E, Ravizza M, et al. Antiretroviral treatment in pregnancy: a six-year perspective on recent trends in prescription patterns, viral load suppression, and pregnancy outcomes. AIDS Patient Care STDS. 2009;23(7):513-520.

13. Gingelmaier A, Eberle J, Kost BP, et al. Protease inhibitor-based antiretroviral prophylaxis during pregnancy and the development of drug resistance. Clin Infect Dis. 2010;50(6):890-894.

14. Souda S, Gaseitsiwe S, Georgette N, et al. No clinically significant drug resistance mutations in HIV-1 subtype $\mathrm{C}$ infected women after discontinuation of NRTI-based or PI-based HAART for PMTCT In Botswana. J Acquir Immune Defic Syndr. March 28, 2013. [Epub ahead of print.]

15. Briand N, Mandelbrot L, Blanche S, et al. Previous antiretroviral therapy for prevention of mother-to-child transmission of HIV does not hamper the initial response to PI-based multitherapy during subsequent pregnancy. J Acquir Immune Defic Syndr. 2011;57(2):126-135.

16. Ellis GM, Huang S, Hitti J, Frenkel LM, Team PS. Selection of HIV resistance associated with antiretroviral therapy initiated due to pregnancy and suspended postpartum. J Acquir Immune Defic Syndr. 2011;58(3):241-247.

17. Weinberg A, Forster-Harwood J, Davies J, et al. Safety and tolerability of antiretrovirals during pregnancy. Infect Dis Obst Gynecol. 2011;2011:867674.

18. Ouyang DW, Brogly SB, Lu M, et al. Lack of increased hepatotoxicity in HIV-infected pregnant women receiving nevirapine compared with other antiretrovirals. AIDS. 2010;24(1):109-114.

19. Lyons F, Hopkins S, Kelleher B, et al. Maternal hepatotoxicity with nevirapine as part of combination antiretroviral therapy in pregnancy. HIV Med. 2006;7(4):255-260.

20. Hitti J, Frenkel LM, Stek AM, et al. Maternal toxicity with continuous nevirapine in pregnancy: results from PACTG 1022. J Acquir Immune Defic Syndr. 2004;36(3):772-776.

21. Gisolf EH, Dreezen C, Danner SA, Weel JL, Weverling GJ; Prometheus Study Group. Risk factors for hepatotoxicity in HIV-1-infected patients receiving ritonavir and saquinavir with or without stavudine. Prometheus Study Group. Clin Infect Dis. 2000;31(5):1234-1239.

22. Sulkowski MS, Mehta SH, Chaisson RE, Thomas DL, Moore RD. Hepatotoxicity associated with protease inhibitor-based antiretroviral regimens with or without concurrent ritonavir. AIDS. 2004;18(17): 2277-2284

23. Torti C, Lapadula G, Antinori A, et al. Hyperbilirubinemia during atazanavir treatment in 2,404 patients in the Italian atazanavir expanded access program and MASTER Cohorts. Infection. 2009;37(3):244-249.
24. Zhang D, Chando TJ, Everett DW, Patten CJ, Dehal SS, Humphreys WG. In vitro inhibition of UDP glucuronosyltransferases by atazanavir and other HIV protease inhibitors and the relationship of this property to in vivo bilirubin glucuronidation. Drug Metab Dispos. 2005;33(11): 1729-1739.

25. Rayner CR, Esch LD, Wynn HE, Eales R. Symptomatic hyperbilirubinemia with indinavir/ritonavir-containing regimen. Ann Pharmacother. 2001;35(11):1391-1395.

26. Hamada Y, Nishijima T, Watanabe K, et al. High incidence of renal stones among HIV-infected patients on ritonavir-boosted atazanavir than in those receiving other protease inhibitor-containing antiretroviral therapy. Clin Infect Dis. 2012;55(9):1262-1269.

27. Gavard L, Gil S, Peytavin G, et al. Placental transfer of lopinavir/ ritonavir in the ex vivo human cotyledon perfusion model. Am J Obstet Gynecol. 2006;195(1):296-301.

28. Ceccaldi PF, Gavard L, Mandelbrot L, et al. Functional role of p-glycoprotein and binding protein effect on the placental transfer of lopinavir/ritonavir in the ex vivo human perfusion model. Obstet Gynecol Int. 2009;2009:726593.

29. Forestier F, de Renty P, Peytavin G, Dohin E, Farinotti R, Mandelbrot L. Maternal-fetal transfer of saquinavir studied in the ex vivo placental perfusion model. Am J Obstet Gynecol. 2001;185(1):178-181.

30. Casey BM, Bawdon RE. Placental transfer of ritonavir with zidovudine in the ex vivo placental perfusion model. Am J Obstet Gynecol. 1998;179(3 Pt 1):758-761.

31. Bawdon RE. The ex vivo human placental transfer of the anti-HIV nucleoside inhibitor abacavir and the protease inhibitor amprenavir. Infect Dis Obstet Gynecol. 1998;6(6):244-246.

32. Marzolini C, Rudin C, Decosterd LA, et al. Transplacental passage of protease inhibitors at delivery. AIDS. 2002;16(6):889-893.

33. Mirochnick M, Dorenbaum A, Holland D, et al. Concentrations of protease inhibitors in cord blood after in utero exposure. Pediatr Infect Dis J. 2002;21(9):835-838.

34. Chappuy H, Treluyer JM, Rey E, et al. Maternal-fetal transfer and amniotic fluid accumulation of protease inhibitors in pregnant women who are infected with human immunodeficiency virus. Am J Obstet Gynecol. 2004;191(2):558-562.

35. Ripamonti D, Cattaneo D, Maggiolo F, et al. Atazanavir plus low-dose ritonavir in pregnancy: pharmacokinetics and placental transfer. AIDS. 2007;21(18):2409-2415.

36. Roberts SS, Martinez M, Covington DL, Rode RA, Pasley MV, Woodward WC. Lopinavir/ritonavir in pregnancy. J Acquir Immune Defic Syndr. 2009;51(4):456-461.

37. Esker S, Albano J, Uy J, et al. Monitoring the risk of birth defects associated with atazanavir exposure in pregnancy. AIDS Patient Care STDS. 2012;26(6):307-311.

38. Cotter AM, Garcia AG, Duthely ML, Luke B, O’Sullivan MJ. Is antiretroviral therapy during pregnancy associated with an increased risk of preterm delivery, low birth weight, or stillbirth? J Infect Dis. 2006;193(9):1195-1201.

39. Kourtis AP, Schmid CH, Jamieson DJ, Lau J. Use of antiretroviral therapy in pregnant HIV-infected women and the risk of premature delivery: a meta-analysis. AIDS. 2007;21(5):607-615.

40. Watts DH, Williams PL, Kacanek D, et al. Combination antiretroviral use and preterm birth. J Infect Dis. 2013;207(4):612-621.

41. Fiore S, Ferrazzi E, Newell ML, Trabattoni D, Clerici M. Protease inhibitor-associated increased risk of preterm delivery is an immunological complication of therapy. J Infect Dis. 2007;195(6): 914-916.

42. Grosch-Woerner I, Puch K, Maier RF, et al. Increased rate of prematurity associated with antenatal antiretroviral therapy in a German/Austrian cohort of HIV-1-infected women. HIV Med. 2008;9(1):6-13.

43. Yanovski JA, Miller KD, Kino T, et al. Endocrine and metabolic evaluation of human immunodeficiency virus-infected patients with evidence of protease inhibitor-associated lipodystrophy. J Clin Endocrinol Metab. 1999;84(6):1925-1931. 
44. Cheshire M, Kingston M, McQuillan O, Gittins M. Are HIV-related factors associated with pre-term delivery in a UK inner city setting? $J$ Int AIDS Soc. 2012;15(6):18223.

45. Azria E, Moutafoff C, Schmitz T, et al. Pregnancy outcomes in women with HIV type-1 receiving a lopinavir/ritonavir-containing regimen. Antivir Ther. 2009;14(3):423-432.

46. Patel K, Shapiro DE, Brogly SB, et al. Prenatal protease inhibitor use and risk of preterm birth among HIV-infected women initiating antiretroviral drugs during pregnancy. J Infect Dis. 2010;201(7):1035-1044.

47. Sibiude J, Warszawski J, Tubiana R, et al. Premature delivery in HIV-infected women starting protease inhibitor therapy during pregnancy: role of the ritonavir boost? Clin Infect Dis. 2012;54(9): 1348-1360.

48. Powis KM, Kitch D, Ogwu A, et al. Increased risk of preterm delivery among HIV-infected women randomized to protease versus nucleoside reverse transcriptase inhibitor-based HAART during pregnancy. $J$ Infect Dis. 2011;204(4):506-514.

49. Townsend CL, Tookey PA, Newell ML, Cortina-Borja M. Antiretroviral therapy in pregnancy: balancing the risk of preterm delivery with prevention of mother-to-child HIV transmission. Antivir Ther. 2010;15(5):775-783.

50. Townsend CL, Cortina-Borja M, Peckham CS, Tookey PA Antiretroviral therapy and premature delivery in diagnosed HIVinfected women in the United Kingdom and Ireland. AIDS. 2007;21(8): 1019-1026.

51. Shapiro RL, Ribaudo H, Powis K, Chen J, Parekh N. Extended antenatal use of triple antiretroviral therapy for prevention of mother-to-child transmission of HIV-1 correlates with favorable pregnancy outcomes. AIDS. 2012;26(1):120-121.

52. Chen JY, Ribaudo HJ, Souda S, et al. Highly active antiretroviral therapy and adverse birth outcomes among HIV-infected women in Botswana. J Infect Dis. 2012;206(11):1695-1705.

53. Parekh N, Ribaudo H, Souda S, et al. Risk factors for very preterm delivery and delivery of very-small-for-gestational-age infants among HIV-exposed and HIV-unexposed infants in Botswana. Int J Gynaecol Obstet. 2011;115(1):20-25.

54. Haeri S, Shauer M, Dale M, et al. Obstetric and newborn infant outcomes in human immunodeficiency virus-infected women who receive highly active antiretroviral therapy. Am J Obstet Gynecol. 2009;201(3):315. e311-e315.

55. Dola CP, Khan R, DeNicola N, et al. Combination antiretroviral therapy with protease inhibitors in HIV-infected pregnancy. J Perinat Med. 2011;40(1):51-55

56. Briand N, Mandelbrot L, Le Chenadec J, et al. No relation between inutero exposure to HAART and intrauterine growth retardation. AIDS. 2009;23(10):1235-1243.

57. Ivanovic J, Nicastri E, Anceschi MM, et al. Transplacental transfer of antiretroviral drugs and newborn birth weight in HIV-infected pregnant women. Current HIV Res. 2009;7(6):620-625.

58. Wimalasundera RC, Larbalestier N, Smith JH, et al. Pre-eclampsia, antiretroviral therapy, and immune reconstitution. Lancet. 2002; 360(9340):1152-1154

59. Mawson AR. Effects of antiretroviral therapy on occurrence of preeclampsia. Lancet. 2003;361(9354):347-348.

60. Frank KA, Buchmann EJ, Schackis RC. Does human immunodeficiency virus infection protect against pre-eclampsia-eclampsia? Obstet Gynecol. 2004;104(2):238-242.

61. Mattar R, Amed AM, Lindsey PC, Sass N, Daher S. Pre-eclampsia and HIV infection. Eur J Obstet Gynecol Reprod Biol. 2004;117(2): 240-241.

62. Suy A, Martinez E, Coll O, et al. Increased risk of pre-eclampsia and fetal death in HIV-infected pregnant women receiving highly active antiretroviral therapy. AIDS. 2006;20(1):59-66.

63. Boyajian T, Shah PS, Murphy KE. Risk of pre-eclampsia in HIV-positive pregnant women receiving HAART: a matched cohort study. J Obstet Gynaecol Can. 2012;34(2):136-141.
64. Noor MA, Parker RA, O’Mara E, et al. The effects of HIV protease inhibitors atazanavir and lopinavir/ritonavir on insulin sensitivity in HIV-seronegative healthy adults. AIDS. 2004;18(16): 2137-2144.

65. Noor MA, Flint OP, Maa JF, Parker RA. Effects of atazanavir/ritonavir and lopinavir/ritonavir on glucose uptake and insulin sensitivity: demonstrable differences in vitro and clinically. AIDS. 2006;20(14): 1813-1821.

66. Noor MA. The role of protease inhibitors in the pathogenesis of HIV-associated insulin resistance: cellular mechanisms and clinical implications. Curr HIV/AIDS Rep. 2007;4(3):126-134.

67. Watts DH, Balasubramanian R, Maupin RT Jr, et al. Maternal toxicity and pregnancy complications in human immunodeficiency virusinfected women receiving antiretroviral therapy: PACTG 316. Am J Obstet Gynecol. 2004;190(2):506-516.

68. El Beitune P, Duarte G, Foss MC, et al. Effect of antiretroviral agents on carbohydrate metabolism in HIV-1 infected pregnant women. Diabetes Metab Res Rev. 2006;22(1):59-63.

69. Gonzalez-Tome MI, Ramos Amador JT, Guillen S, et al. Gestational diabetes mellitus in a cohort of HIV-1 infected women. HIV Med. 2008;9(10):868-874.

70. Tang JH, Sheffield JS, Grimes J, et al. Effect of protease inhibitor therapy on glucose intolerance in pregnancy. Obstet Gynecol. 2006;107(5):1115-1119.

71. Hitti J, Andersen J, McComsey G, et al. Protease inhibitor-based antiretroviral therapy and glucose tolerance in pregnancy: AIDS Clinical Trials Group A5084. Am J Obstet Gynecol. 2007;196(4):331. e331-e337.

72. Anger GJ, Piquette-Miller M. Mechanisms of reduced maternal and fetal lopinavir exposure in a rat model of gestational diabetes. Drug Metab Dispos. 2011;39(10):1850-1859.

73. Olivero OA, Fernandez JJ, Antiochos BB, Wagner JL, St Claire ME, Poirier MC. Transplacental genotoxicity of combined antiretroviral nucleoside analogue therapy in Erythrocebus patas monkeys. J Acquir Immune Defic Syndr. 2002;29(4):323-329.

74. Olivero OA. Relevance of experimental models for investigation of genotoxicity induced by antiretroviral therapy during human pregnancy. Mutat Res. 2008;658(3):184-190.

75. European Collaborative Study. Exposure to antiretroviral therapy in utero or early life: the health of uninfected children born to HIV-infected women. J Acquir Immune Defic Syndr. 2003;32(4): 380-387.

76. Gills JJ, Lopiccolo J, Tsurutani J, et al. Nelfinavir, a lead HIV protease inhibitor, is a broad-spectrum, anticancer agent that induces endoplasmic reticulum stress, autophagy, and apoptosis in vitro and in vivo. Clin Cancer Res. 2007;13(17):5183-5194.

77. Gills JJ, Lopiccolo J, Dennis PA. Nelfinavir, a new anti-cancer drug with pleiotropic effects and many paths to autophagy. Autophagy. 2008;4(1):107-109.

78. Mandelbrot L, Mazy F, Floch-Tudal C, et al. Atazanavir in pregnancy: impact on neonatal hyperbilirubinemia. Eur J Obstet Gynecol Reprod Biol. 2011;157(1):18-21.

79. Conradie F, Zorrilla C, Josipovic D, et al. Safety and exposure of oncedaily ritonavir-boosted atazanavir in HIV-infected pregnant women. HIV Med. 2011;12(9):570-579.

80. Le Chenadec J, Mayaux MJ, Guihenneuc-Jouyaux C, Blanche S; Enquete Perinatale Francaise Study Group. Perinatal antiretroviral treatment and hematopoiesis in HIV-uninfected infants. AIDS. 2003;17(14):2053-2061.

81. European Collaborative Study. Levels and patterns of neutrophil cell counts over the first 8 years of life in children of HIV-1-infected mothers AIDS. 2004;18(15):2009-2017.

82. Feiterna-Sperling C, Weizsaecker K, Buhrer C, et al. Hematologic effects of maternal antiretroviral therapy and transmission prophylaxis in HIV-1-exposed uninfected newborn infants. J Acquir Immune Defic Syndr. 2007;45(1):43-51. 
83. Heidari S, Mofenson L, Cotton MF, Marlink R, Cahn P, Katabira E. Antiretroviral drugs for preventing mother-to-child transmission of HIV: a review of potential effects on HIV-exposed but uninfected children. $J$ Acquir Immune Defic Syndr. 2011;57(4):290-296.

84. Simon A, Warszawski J, Kariyawasam D, et al. Association of prenatal and postnatal exposure to lopinavir-ritonavir and adrenal dysfunction among uninfected infants of HIV-infected mothers. JAMA. 2011;306(1):70-78
85. Tubiana R, Mandelbrot L, Delmas S, et al; and the Primeva Study Group. LPV/r monotherapy during pregnancy for PMTCT of HIV-1: the PRIMEVA/ANRS 135 randomized trial, pregnancy outcomes. Paper presented at the 18th Conference on Retroviruses and Opportunistic Infections, Boston, MA, February 27 to March 2, 2011.

\section{Publish your work in this journal}

HIV/AIDS - Research and Palliative Care is an international, peerreviewed open-access journal focusing on advances in research in HIV, its clinical progression and management options including antiviral treatment, palliative care and public healthcare policies to control viral spread. The journal welcomes original research, basic science, clinical \& epidemiological studies, reviews \& evaluations, expert opinion \& commentary, case reports \& extended reports. The manuscript management system is completely online and includes a very quick and fair peer-review system. Visit http://www.dovepress.com/ testimonials.php to read real quotes from published authors.

Submit your manuscript here: http://www.dovepress.com/hivaids---research-and-palliative-care-journal 